\title{
Role of repeat CT in mild to moderate head injury: an institutional study
}

\author{
Madhusudhan Nagesh, MBBS, Kautilya Rajendrakumar Patel, MBBS, Ajit Mishra, MCh, \\ Ujwal Yeole, MCh, Andiperumal R. Prabhuraj, MCh, and Dhaval Shukla, MCh
}

Department of Neurosurgery, National Institute of Mental Health and Neurosciences (NIMHANS), Bengaluru, Karnataka, India

OBJECTIVE Patients with traumatic brain injury (TBI) often undergo repeat head CT scans to identify the possible progression of injury. The objective of this study is to evaluate the need for routine repeat head CT scans in patients with mild to moderate head injury and an initial positive abnormal CT scan.

METHODS This is a retrospective study of patients presenting to the emergency department from January 2016 to December 2017 with Glasgow Coma Scale (GCS) scores > 8 and an initial abnormal CT scan, who underwent repeat CT during their in-hospital medical management. Patients who underwent surgery after the first CT scan, had a GCS score $<$, or had a normal initial CT scan were excluded. Demographic, medical history, and physical examination details were collected, and CT scans were reviewed. Radiological deterioration, neurological deterioration, and/or the need for neurosurgical intervention were the primary outcome variables.

RESULTS A total of 1033 patients were included in this study. These patients underwent at least two CT scans on an inpatient basis. Of these 1033 patients, 54.1\% had mild head injury and 45.9\% had moderate head injury based on GCS score at admission. The most common diagnosis was contusion (43.8\%), followed by extradural hematoma (28.8\%) and subdural hematoma (26.6\%). A total of 2636 CT scans were performed for 1033 patients, with a mean of 2.55 per patient. Of these, $25(2.4 \%)$ had neurological deterioration, $90(8.7 \%)$ had a progression of an existing lesion or appearance of a new lesion on repeat CT, and 101 (9.8\%) required neurosurgical intervention. Seventy-five patients underwent surgery due to worsening of repeat CT without neurological deterioration, so the average number of repeat CT scans required to identify one such patient was 21 .3. On multiple logistic regression, GCS score at admission $(p=0.024)$, abnormal international normalized ratio (INR; $p<0.001)$, midline shift $(p=0.005)$, effaced basal cisterns $(p<0.001)$, and multiple hemorrhagic lesions ( $p=0.010$ ) were associated with worsening of repeat $C T$, neurological deterioration, and/or need for neurosurgical intervention.

CONCLUSIONS The role of routine repeat head CT in medically managed patients with head injury is controversial. The authors have tried to study the various factors that are associated with neurological deterioration, radiological deterioration, and/or need for neurosurgical intervention. In this study the authors found lower GCS score at admission, abnormal INR, presence of midline shift, effaced basal cisterns, and multiple lesions on initial CT to be significantly associated with the above outcomes.

https://thejns.org/doi/abs/10.3171/2019.8.FOCUS19527

KEYWORDS traumatic brain injury; computed tomography; repeat imaging

$\mathrm{A}$ PPROXIMATELY 2 million people sustain traumatic brain injury (TBI) annually in India. A CT scan of the head is the initial choice of radiological investigation to evaluate patients with suspected head injury. ${ }^{10}$ The need for neurosurgical intervention is based on the clinical status of the patient and the radiological finding on head CT.
Controversy arises in the management of patients with an initial abnormal head CT scan after TBI who do not require immediate surgery. A subset of such patients is managed on an in-hospital basis with frequent clinical examination, intensive care unit (ICU) care and monitoring, and/or repeat head CT. The role of routine repeat head CT is to identify radiological progression of the lesion before

ABBREVIATIONS ED = emergency department; EDH = extradural hematoma; ENT = ear/nose/throat; GCS = Glasgow Coma Scale; ICP = intracranial pressure; ICU = intensive care unit; INR = international normalized ratio; IPH = intraparenchymal hemorrhage; NIMHANS = National Institute of Mental Health and Neurosciences; PT = prothrombin time; $\mathrm{SAH}=$ subarachnoid hemorrhage; $\mathrm{SDH}=$ subdural hematoma; $\mathrm{TBI}=$ traumatic brain injury.

SUBMITTED June 30, 2019. ACCEPTED August 20, 2019.

INCLUDE WHEN CITING DOI: 10.3171/2019.8.FOCUS19527. 


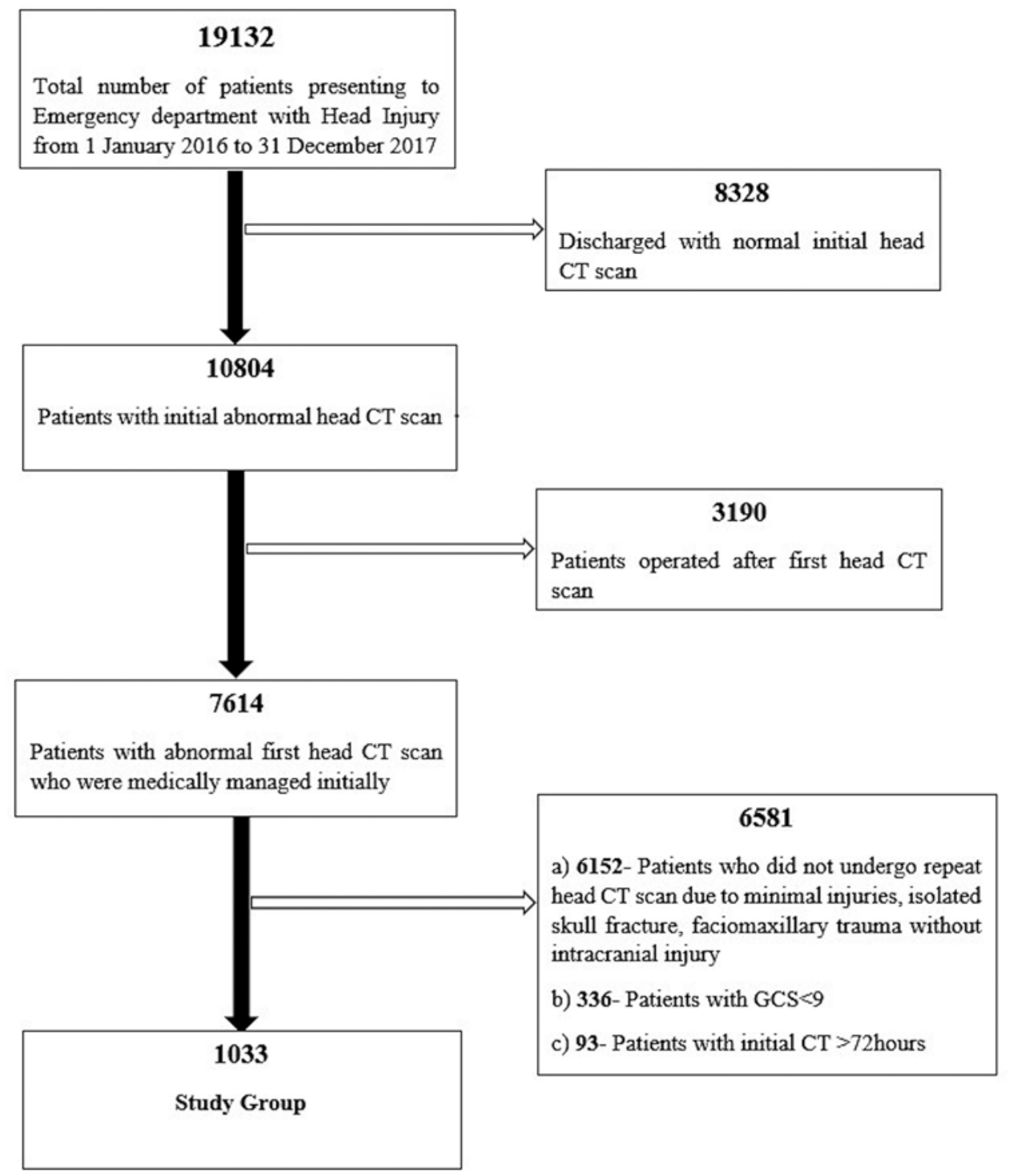

FIG. 1. Flowchart of patient selection.

clinical deterioration, which would lead to neurosurgical intervention. Some studies have shown that a routine repeat head CT scan is not indicated unless there is a neurological deterioration, ${ }^{1,2,16,17}$ while others suggest routine repeat imaging is necessary to identify the subset of patients without neurological deterioration who require neurosurgical intervention. $7,14,15$

The aim of this study was to evaluate the role of repeat CT imaging in patients with mild to moderate head injury who were initially treated medically. We also studied the factors associated with radiological progression that possibly predict the requirement of neurosurgical intervention.

\section{Methods}

\section{Study Design}

A retrospective study of patients presenting to the emergency department (ED) at the National Institute of Mental Health and Neurosciences (NIMHANS) in Ban- galore, India, with a suspected head injury from January 1, 2016, to December 31, 2017, was conducted. Patients with a Glasgow Coma Scale (GCS) score $>8$ and initial abnormal head CT scan, who were medically managed on an in-hospital basis, were included. Patients who underwent immediate surgery after the first CT scan were excluded. In addition, patients with a normal CT scan, initial abnormal CT scan with minimal injuries, isolated subarachnoid hemorrhage $(\mathrm{SAH})$, isolated cranial vault fractures, and faciomaxillary injuries without intracranial injury, and who underwent their first scan more than 72 hours since the injury were also excluded. The study group included 1033 patients who underwent in-hospital medical management after initial abnormal CT and underwent repeat CT during their hospital stay (Fig. 1).

An abnormal CT scan included any of the following lesions: extradural hematoma (EDH), acute subdural hematoma (SDH), SAH, contusion, or intraparenchymal hemorrhage (IPH). All patients in the study group were admitted 
in the ED and underwent repeat head CT, either after neurological deterioration or on a routine basis. No standard protocol was followed for ordering routine repeat CT; the decision was based on the neurosurgery emergency team.

\section{Outcomes}

The primary outcome variables were neurological deterioration, radiological deterioration, and/or need for neurosurgical intervention. Neurological deterioration was defined as 1) decrease in GCS score by 1 or more; 2) newonset neurological deficits such as pupillary asymmetry or weakness of limbs; or 3) death. Radiological deterioration on repeat head CT was defined as 1) progression or increase in size of the hemorrhagic lesion seen on initial CT; 2) occurrence of a new lesion; or 3) increased midline shift, mass effect, effacement of basal cisterns, or herniation. Neurosurgical intervention meant operative management.

\section{Data Collection}

Medical records and CT scans of all patients in the study group were reviewed. Variables collected from case files included age, sex, mode of injury, history of alcohol intake, and time of injury. Initial GCS score, neurological examination, time to first CT scan from injury, time to repeat CT scan, follow-up examination, and need for neurosurgical intervention were obtained from case files. The initial CT scan and repeat CT scans were reviewed for worsening of the lesion, the appearance of a new lesion, increased midline shift, mass effect, effacement of basal cisterns, presence of $\mathrm{SAH}$, and multiple lesions.

\section{Statistical Analysis}

Demographic variables were analyzed. Patients with routine repeat head CT scans with a composite outcome of radiological deterioration, clinical deterioration, and/or need for neurosurgical intervention were compared to patients with none of these outcomes. Statistical analysis was performed using IBM SPSS software (version 23, IBM Corp.). Categorical variables were analyzed using the chisquare and Fisher's exact tests. Numerical data were analyzed using the Student t-test and Mann-Whitney U-test. A multivariate logistic regression analysis (stepwise forward model) was performed to identify factors associated with the composite outcome. Statistical significance was kept at $\mathrm{p}<0.05$ for all the comparisons.

\section{Results \\ Description of Study Group}

During the 2-year study period, 19,132 patients presented to the ED with suspected head injury, and 1033 patients met the inclusion criteria (Fig. 1). The mean patient age was $37.4 \pm 17$ years, and $77.2 \%(n=797)$ of the patients were men. The remainder of the demographic details are noted in Table 1. The median GCS score at admission was 14. The mean time to first CT scan since injury was 7.9 \pm 9.3 hours (range 0.5-72 hours). Repeat head CT scans were performed after an average of $9.9 \pm 6.8$ hours from the initial CT scan.
TABLE 1. Characteristics of the study population $(n=1033)$

\begin{tabular}{|c|c|}
\hline Variable & Value \\
\hline Mean age $\pm S D$, yrs & $37.4 \pm 17$ \\
\hline Age $\leq 18$ yrs & $121(11.7)$ \\
\hline Age $\geq 65$ yrs & $78(7.6)$ \\
\hline Females & $236(22.8)$ \\
\hline \multicolumn{2}{|l|}{ Mode of trauma } \\
\hline Road traffic accidents & $788(76.3)$ \\
\hline Fall & $200(19.4)$ \\
\hline Assault & $24(2.3)$ \\
\hline Others & $21(2.0)$ \\
\hline Alcohol consumption & $239(23.1)$ \\
\hline \multicolumn{2}{|l|}{ Symptoms } \\
\hline Loss of consciousness & $600(58.1)$ \\
\hline Seizures & $71(6.9)$ \\
\hline Vomiting & $600(58.1)$ \\
\hline ENT bleed & $481(46.6)$ \\
\hline Mean GCS score at admission \pm SD (median) & $13.12 \pm 2.046(14)$ \\
\hline Mild head injury & $559(54.1)$ \\
\hline Moderate head injury & $474(45.9)$ \\
\hline $\begin{array}{l}\text { Mean time to 1st scan since injury } \pm \text { SD (median), } \\
\text { hrs }\end{array}$ & $7.9 \pm 9.3(5)$ \\
\hline Mean interval btwn 1st \& 2nd scan \pm SD, hrs & $9.9 \pm 6.8$ \\
\hline Mean total no. of scans \pm SD & $2.55 \pm 0.8$ \\
\hline \multicolumn{2}{|l|}{ CT lesions/diagnosis } \\
\hline Contusion & $452(43.8)$ \\
\hline $\mathrm{EDH}$ & $298(28.8)$ \\
\hline Acute SDH & $275(26.6)$ \\
\hline Diffuse axonal injury & $7(0.7)$ \\
\hline Intraventricular hemorrhage & $1(0.1)$ \\
\hline \multicolumn{2}{|l|}{ Laboratory investigations } \\
\hline Low platelet count, $<150,000$ & $110(10.6)$ \\
\hline Abnormal PT, >15.4 & $258(25.0)$ \\
\hline Abnormal INR, >1.5 & $19(1.8)$ \\
\hline Abnormal APTT, >39.4 & $19(5.7)$ \\
\hline \multicolumn{2}{|l|}{ CT findings } \\
\hline $\mathrm{SAH}$ & $556(53.8)$ \\
\hline Multiple lesions & $409(39.6)$ \\
\hline Midline shift & $407(39.4)$ \\
\hline Effacement of basal cisterns & $103(10)$ \\
\hline Cranial vault fracture & $573(55.5)$ \\
\hline Contrecoup injury & $311(30.1)$ \\
\hline Radiological deterioration & $90(8.7)$ \\
\hline Clinical deterioration & $25(2.4)$ \\
\hline Neurosurgical intervention & $101(9.8)$ \\
\hline
\end{tabular}

APTT = activated partial thromboplastin time.

Categorical parameters are displayed as actual values and percentages, and continuous parameters as means and standard deviations. 


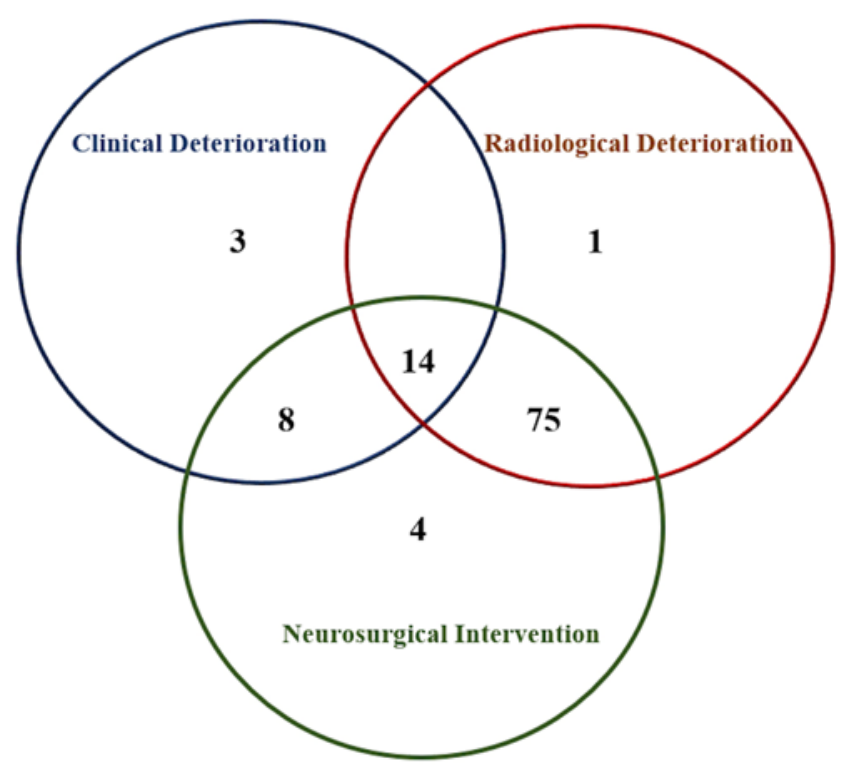

FIG. 2. Venn diagram representing overlap of the patients with clinical deterioration, radiological deterioration, and need for neurosurgical intervention.

A total of 2636 scans were performed for 1033 patients, with a mean of 2.55 scans per patient. All patients in our study group underwent a second (repeat) CT after the initial abnormal CT scan. Four hundred eleven patients (39.8\%) underwent a third CT scan, and 158 (15.3\%) underwent subsequent scans before either being discharged or having one of the primary outcomes.

Of the study group, 90 patients $(8.7 \%)$ had radiological deterioration (at a mean of 31.88 hours), 25 patients (2.4\%) had neurological deterioration (at a mean of 35.24 hours), and 101 patients (9.8\%) underwent neurosurgical intervention (at a mean of 33.00 hours). The Venn diagram in Fig. 2 illustrates the primary outcomes of this study. Seventyfive patients underwent surgery due to worsening of repeat CT without neurological deterioration; thus on average the number of repeat CT scans required to identify one such patient was 21.3.

\section{Stratification by Composite Outcome}

The study group was divided into two groups, one with composite outcomes such as neurological deterioration, radiological deterioration, and/or need for neurosurgical intervention, and the other group without any of these outcomes. Patients with the composite outcome $(n=105$, $10.2 \%$ ) were compared with patients without any of the primary outcomes $(n=928,89.8 \%)$; the characteristics of these two groups are listed in Table 2.

A total of 270 scans were performed for the 105 patients having a composite outcome, with a mean of 2.57 scans per patient. Of the patients who needed neurosurgical intervention, 64 (63.4\%) underwent surgery after the second CT scan, and 37 (36.6\%) underwent surgery after subsequent CT scans.

Both groups were comparable in terms of age $(\mathrm{p}=$ $0.843)$, mode of trauma (0.172), time to first scan since injury (0.889), other associated symptoms, and primary CT diagnosis (0.494). On univariate analysis, female sex ( $\mathrm{p}$ $=0.027)$, ear $/$ nose/throat $(E N T)$ bleed $(p=0.037)$, lower mean GCS score at admission $(\mathrm{p}<0.001)$, international normalized ratio (INR) $>1.5(\mathrm{p}<0.001)$, prothrombin time $(\mathrm{PT})>15.4(\mathrm{p}=0.004)$, presence of SAH $(\mathrm{p}<0.001)$, midline shift $(\mathrm{p}<0.001)$, effaced basal cisterns $(\mathrm{p}<0.001)$, multiple hemorrhagic lesions ( $p<0.001)$, and contrecoup injury $(\mathrm{p}=0.001)$ on initial CT scan were associated with composite outcome.

\section{Risk Factors for Composite Outcomes}

On stepwise logistic regression of the significant parameters on univariate analysis, mean GCS score at admission ( $\mathrm{p}=0.024)$, abnormal INR ( $<<0.001)$, midline shift $(p=0.005)$, effaced basal cisterns $(p<0.001)$, and multiple hemorrhagic lesions $(p=0.010)$ were found to be independently associated with worsening of repeat CT, neurological deterioration, and/or need for surgery.

\section{Stratification by Head Injury Severity}

We analyzed the above factors separately for mild head injury and moderate head injury between patients with the composite outcome and patients without. In a subset of patients with mild head injury (54.1\%), the presence of the following risk factors in the initial CT scan would indicate progression to one of the composite outcomes: 1) midline shift $(p=0.006), 2)$ effaced basal cisterns $(p<0.001), 3)$ multiple hemorrhagic lesions $(p=0.001)$, and 4$)$ contrecoup injury $(\mathrm{p}=0.003)$. In patients with moderate head injury $(45.9 \%)$, effaced basal cisterns $(p=0.001)$ and multiple hemorrhagic lesions $(p=0.032)$ on the initial CT scan were identified as statistically significant associations with any of the composite outcomes.

\section{Discussion}

The goal of management of TBI is to prevent secondary neurological insult through either medical or surgical management, which translates into preventing additional neurological deterioration. Head CT is the initial diagnostic tool used to evaluate patients with suspected head injury. ${ }^{3,10}$ Management of patients with TBI includes neurosurgical intervention if indicated, lowering of intracranial pressure (ICP), and prevention of hypotension and hypoxia, among others.

A subset of patients presenting to the ED with an initial negative head CT scan, no obvious neurological deficits, and a GCS score of 15 can be discharged. ${ }^{5}$ Patients with an abnormal initial head CT scan and managed medically are monitored by frequent neurological examinations. Patients who have neurological deterioration undergo a repeat head CT scan and may require neurosurgical intervention based on its results. ${ }^{8}$

The controversy arises in monitoring medically managed patients with routine repeat head CT scan when there is no neurological deterioration. Because radiological deterioration in the form of an increase in the size of the primary lesion, appearance of a new lesion, increased edema, mass effect, effacement of basal cisterns, and uncal herniation precedes neurological deterioration in the form of a decrease in GCS score, new-onset neurological 
TABLE 2. Comparison of variables in patients with versus without composite outcome

\begin{tabular}{|c|c|c|c|}
\hline Parameter & Pts w/o Composite Outcome & Pts w/ Composite Outcome & p Value \\
\hline No. of pts & $928(89.8)$ & $105(10.2)$ & \\
\hline Mean age $\pm S D$, yrs & $37.4 \pm 17.1$ & $37.27 \pm 16.8$ & 0.843 \\
\hline Females & $203(21.9)$ & $33(31.4)$ & 0.027 \\
\hline Mode of trauma & & & 0.172 \\
\hline Road traffic accidents & $699(75.3)$ & $89(84.8)$ & \\
\hline Fall & $188(20.3)$ & $12(11.4)$ & \\
\hline Assault & $22(2.4)$ & $2(1.9)$ & \\
\hline Others & $19(20)$ & $2(1.9)$ & \\
\hline Alcohol consumption & $212(22.8)$ & $27(25.7)$ & 0.509 \\
\hline \multicolumn{4}{|l|}{ Symptoms } \\
\hline Loss of consciousness & $535(57.7)$ & $65(61.9)$ & 0.402 \\
\hline Seizures & $67(7.2)$ & $4(3.8)$ & 0.190 \\
\hline Vomiting & $537(57.9)$ & $63(60)$ & 0.675 \\
\hline ENT bleed & $422(45.5)$ & $59(56.2)$ & 0.037 \\
\hline Mean GCS score at admission \pm SD & $13.23 \pm 2.0$ & $12.15 \pm 2.1$ & $<0.001$ \\
\hline Mild head injury & $528(56.9)$ & $31(29.5)$ & $<0.001$ \\
\hline Moderate head injury & $400(43.1)$ & $74(70.5)$ & \\
\hline Mean duration until 1st scan since injury $\pm S D$, hrs & $7.9 \pm 9.2$ & $8.05 \pm 9.5$ & 0.889 \\
\hline CT lesions/diagnosis & & & 0.494 \\
\hline Contusion & $400(43.1)$ & $52(49.5)$ & \\
\hline $\mathrm{EDH}$ & $270(29.1)$ & $28(26.7)$ & \\
\hline SDH & $250(26.9)$ & $25(23.8)$ & \\
\hline \multicolumn{4}{|l|}{ Laboratory investigations* } \\
\hline Low platelet count & $96(11)$ & $14(13.3)$ & 0.469 \\
\hline Abnormal PT & $219(25.3)$ & $39(38.6)$ & 0.004 \\
\hline Abnormal INR & $11(1.3)$ & $8(7.8)$ & $<0.001$ \\
\hline Abnormal APTT & $54(6.2)$ & $5(4.9)$ & 0.596 \\
\hline \multicolumn{4}{|l|}{ CT findings } \\
\hline SAH & $480(51.7)$ & $76(72.4)$ & $<0.001$ \\
\hline Multiple lesions & $339(36.5)$ & $70(66.7)$ & $<0.001$ \\
\hline Midline shift & $337(36.3)$ & $70(66.7)$ & $<0.001$ \\
\hline Effacement of basal cisterns & $374(40.3)$ & $84(80)$ & $<0.001$ \\
\hline Cranial vault fracture & $509(54.8)$ & $64(61.0)$ & 0.233 \\
\hline Contrecoup injury & $264(28.4)$ & $47(44.8)$ & 0.001 \\
\hline
\end{tabular}

Pts = patients.

Composite outcome $=$ radiological deterioration, clinical deterioration, and/or need for neurosurgical intervention. Categorical parameters are displayed as actual values and percentages, and continuous parameters as means and standard deviations. Boldface type indicates statistical significance.

* Some categories were missing data for a few patients.

deficits, and increased ICP features, it becomes important to monitor such patients with routine repeat head CT scans. Hence, an early neurosurgical intervention based on routine repeat CT scan findings without neurological deterioration can prevent worsened outcomes.

The role of routine repeat head CT remains unclear in the literature. A systematic review performed by Wang et al. ${ }^{18}$ in 2006 found that neurosurgical intervention due to a routine repeat head CT scan occurred in $0 \%-54 \%$ of patients. These data show that the role of routine repeat CT is unclear and further studies are needed to identify factors determining the progression of injury. Hence, in this study we attempted to evaluate the factors associated with radiological deterioration, neurological deterioration, and/or need for neurosurgical intervention.

Few studies have shown that routine repeat head CT is beneficial. ${ }^{7,14,15,18}$ In a study by Park et al. ${ }^{7}$ in adult patients with GCS scores $>7$, it was reported that $37 \%(n=22)$ underwent surgical intervention due to radiological progression without neurological decline. The mean time between the initial and repeat head CT scan reported was $10.10 \pm$ 7.25 hours. Thorson et al ${ }^{15}$ reported that in patients requir- 
ing neurosurgical intervention, $32 \%-59 \%$ had no neurological decline before worsening of repeat CT. Based on their analysis, altered GCS score, Injury Severity Scale score, and the presence of mass effect were independently associated with worsening of repeat CT.

In contrast, few studies have questioned the role of routine repeat CT in neurologically stable patients. ${ }^{1,4,9,13,16,17} \mathrm{In}$ a study by Van Ornam et al. ${ }^{16}$ in patients with traumatic intracranial hemorrhage and GCS scores $>12$, only 3 patients underwent neurosurgical intervention due to worsening of repeat CT without neurological decline. The number of repeat scans required to identify one patient was 305. In a prospective study performed by Sharifuddin et al. ${ }^{9}$ of patients who underwent neurosurgical intervention after worsened repeat head CT, all patients experienced neurological decline before the repeat CT. These authors found that age $>65$ years, GCS scores $<15$, and multiple hemorrhagic lesions were independently associated with a worse repeat CT scan. Similar results were reported by Velmahos et al., ${ }^{17}$ in which no patient underwent neurosurgical intervention with routine repeat CT and without clinical deterioration.

Clearly, there is no consensus regarding the role of routine repeat head CT scans. At our institute we routinely repeat head CT scans in all patients with TBI who are admitted for observation and medically managed to detect radiological deterioration prior to clinical decline. If there is no deterioration they are discharged and referred to a nonneurosurgical hospital for further treatment and observation, and if they have progression they are managed in the ICU or undergo intervention. Patients with initial abnormal CT with minimal injuries; isolated $\mathrm{SAH}$; isolated skull vault fractures with no history of loss of consciousness, amnesia, vomiting, ENT bleed, or seizures; and a condition that is deemed fit are discharged after the first scan. The mean interval between the initial scan and repeat scan in our study was $9.9 \pm 6.8$ hours, and the mean interval was higher for subsequent scans in the absence of neurological deterioration.

Identifying risk factors associated with the composite outcome is important, which allows us to monitor such patients closely with routine repeat CT scans. The patients without risk factors can be discharged or can undergo less frequent CT scans. In our study after multivariate analysis, we identified 5 risk factors associated with the composite outcome, i.e., radiological or clinical deterioration. These risk factors were lower GCS score at admission, abnormal INR, presence of midline shift, effaced basal cisterns, and multiple lesions on initial scan.

Oertel et al. ${ }^{6}$ and Stein et al. ${ }^{12}$ have reported coagulation abnormalities as a risk factor for radiological deterioration. Stein et al. ${ }^{12}$ stress that the risk of developing progressive or new lesions on repeat CT rose to almost $85 \%$ if one of the coagulation parameters were abnormal at admission. Stein et al..$^{11}$ reported that SDH on initial CT was associated with worsening of repeat CT, whereas Park et al. ${ }^{7}$ reported EDH and intraventricular hemorrhage to be associated with the need for neurosurgical intervention. However, no such significant association over primary location of intracranial hematoma and composite outcome was observed in our study.

\section{Limitations}

There was no standard protocol followed for routine repeat CT scans. If the CT scans of all the patients with head injury and an abnormal first CT scan are repeated, then it will give an actual rate of progression of traumatic intracranial pathology. Although this ideal policy is desirable, it is not feasible and cost-effective. Many abnormal findings on the initial CT scan are of trivial importance, and along with clinical judgment do not warrant a routine repeat CT scan. The purpose of this study was to identify the risk factors of progression in the patients who are admitted for observation.

\section{Conclusions}

Patients with lower GCS score at admission, abnormal INR, presence of midline shift, effaced basal cisterns, and multiple lesions on initial scan definitely require a repeat CT scan of the head to detect early progression of traumatic intracranial pathology prior to neurological deterioration. This procedure will help in prompt treatment, and eventually lead to better clinical outcome.

\section{References}

1. Brown CVR, Zada G, Salim A, Inaba K, Kasotakis G, Hadjizacharia $\mathrm{P}$, et al: Indications for routine repeat head computed tomography (CT) stratified by severity of traumatic brain injury. J Trauma 62:1339-1345, 2007

2. Connon FF, Namdarian B, Ee JLC, Drummond KJ, Miller JA: Do routinely repeated computed tomography scans in traumatic brain injury influence management? A prospective observational study in a level 1 trauma center. Ann Surg 254:1028-1031, 2011

3. Cushman JG, Agarwal N, Fabian TC, Garcia V, Nagy KK, Pasquale MD, et al: Practice management guidelines for the management of mild traumatic brain injury: the EAST practice management guidelines work group. J Trauma 51:1016-1026, 2001

4. Dharap SB, Khandkar AA, Pandey A, Sharma AK: Repeat CT scan in closed head injury. Injury 36:412-416, 2005

5. Jagoda AS, Bazarian JJ, Bruns JJ Jr, Cantrill SV, Gean AD, Howard PK, et al: Clinical policy: neuroimaging and decisionmaking in adult mild traumatic brain injury in the acute setting. Ann Emerg Med 52:714-748, 2008

6. Oertel M, Kelly DF, McArthur D, Boscardin WJ, Glenn TC, Lee JH, et al: Progressive hemorrhage after head trauma: predictors and consequences of the evolving injury. J Neurosurg 96:109-116, 2002

7. Park HK, Joo WI, Chough CK, Cho CB, Lee KJ, Rha HK: The clinical efficacy of repeat brain computed tomography in patients with traumatic intracranial haemorrhage within 24 hours after blunt head injury. Br J Neurosurg 23:617-621, 2009

8. Patel NY, Hoyt DB, Nakaji P, Marshall L, Holbrook T, Coimbra R, et al: Traumatic brain injury: patterns of failure of nonoperative management. J Trauma 48:367-375, 2000

9. Sharifuddin A, Adnan J, Ghani AR, Abdullah JM: The role of repeat head computed tomography in the management of mild traumatic brain injury patients with a positive initial head CT. Med J Malaysia 67:305-308, 2012

10. Stein SC, Ross SE: Minor head injury: a proposed strategy for emergency management. Ann Emerg Med 22:11931196, 1993

11. Stein SC, Spettell C, Young G, Ross SE: Delayed and progressive brain injury in closed-head trauma: radiological demonstration. Neurosurgery 32:25-31, 1993 
12. Stein SC, Young GS, Talucci RC, Greenbaum BH, Ross SE: Delayed brain injury after head trauma: significance of coagulopathy. Neurosurgery 30:160-165, 1992

13. Stippler M, Liu J, Motiei-Langroudi R, Voronovich Z, Yonas H, Davis RB: Complicated mild traumatic brain injury and the need for imaging surveillance. World Neurosurg 105:265-269, 2017

14. Thomas BW, Mejia VA, Maxwell RA, Dart BW, Smith PW, Gallagher MR, et al: Scheduled repeat CT scanning for traumatic brain injury remains important in assessing head injury progression. J Am Coll Surg 210:824-832, 2010

15. Thorson CM, Van Haren RM, Otero CA, Guarch GA, Curia E, Barrera JM, et al: Repeat head computed tomography after minimal brain injury identifies the need for craniotomy in the absence of neurologic change. J Trauma Acute Care Surg 74:967-975, 2013

16. Van Ornam J, Pruitt P, Borczuk P: Is repeat head CT necessary in patients with mild traumatic intracranial hemorrhage. Am J Emerg Med 37:1694-1698, 2019

17. Velmahos GC, Gervasini A, Petrovick L, Dorer DJ, Doran ME, Spaniolas K, et al: Routine repeat head CT for minimal head injury is unnecessary. J Trauma 60:494-501, 2006

18. Wang MC, Linnau KF, Tirschwell DL, Hollingworth W:
Utility of repeat head computed tomography after blunt head trauma: a systematic review. J Trauma 61:226-233, 2006

\section{Disclosures}

The authors report no conflict of interest concerning the materials or methods used in this study or the findings specified in this paper.

\section{Author Contributions}

Conception and design: Prabhuraj, Nagesh, Patel, Mishra, Yeole. Acquisition of data: Nagesh, Patel. Analysis and interpretation of data: Nagesh, Patel, Yeole, Shukla. Drafting the article: Prabhuraj, Nagesh. Critically revising the article: Nagesh, Patel, Mishra, Yeole, Shukla. Reviewed submitted version of manuscript: all authors. Approved the final version of the manuscript on behalf of all authors: Prabhuraj. Statistical analysis: Nagesh, Patel. Study supervision: Prabhuraj, Mishra, Shukla.

\section{Correspondence}

Andiperumal R. Prabhuraj: National Institute of Mental Health and Neurosciences, Karnataka, India.drprabhuraj@yahoo.co.in. 